\title{
0 ABSENTEÍSMO ESCOLAR DE DISCENTES NA CLASSE DE REPETENTES: UM ESTUDO DE CASO ETNOGRÁFICO
}

\author{
THE ABSENTEEISM OF SCHOOL STUDENTS IN A CLASS OF REPEAT \\ STUDENTS: AN ETHNOGRAPHIC CASE STUDY
}

\section{EL ABSENTISMO ESCOLAR DE LOS ALUMNOS REPETIDORES: UN ESTUDIO DE CASO ETNOGRÁFICO}

Suziane de Santana Vasconcellos*

\begin{abstract}
Resumo: Este estudo apresenta discussões referentes ao absenteísmo escolar de discentes segundo a perspectiva dos sujeitos de uma escola pública do estado do Rio de Janeiro. O artigo foi elaborado a partir de uma pesquisa etnográfica que resultou na dissertação de mestrado intitulada A classe de repetentes: um estudo etnográfico, a qual objetivava observar o processo de escolarização de alunas e alunos de uma classe de Ensino Fundamental constituída apenas por repetentes e multirrepetentes. Este estudo etnográfico utilizou recursos como a observação participante, a entrevista etnográfica e a análise documental, que mediante uma análise indutiva resultaram em reflexões e discussões sobre o processo de escolarização das alunas e alunos da classe de repetentes. Dentre estas reflexões e discussões com os sujeitos da pesquisa, o absenteísmo escolar está presente como parte relevante deste processo, sendo assim, espera-se, com este artigo, contribuir para discussões e pesquisas sobre o absenteísmo escolar, repetência e fracasso escolar.
\end{abstract}

Palavras-chave: Absenteísmo escolar. Repetência. Fracasso escolar.

\begin{abstract}
This study presents discussions related to school absenteeism of students from the perspective of the subjects of a public school in the state of Rio de Janeiro, Brazil. The article was developed based on an ethnographic research that resulted in the master thesis entitled The class of repeat students: an ethnographic study, which aimed to observe the school education process of the students of an Elementary School class consisting only of repeat students. This ethnographic study used resources such as participant observation, ethnographic interview and document analysis, which by an inductive analysis resulted in reflections and discussions on the education process of the students of the repeat students' class. Among these reflections and discussions with the research subjects, school absenteeism is present as a relevant part of this process, so we hope, with this article, to contribute to discussions and researches on school absenteeism, grade repetition and academic failure.
\end{abstract}

Keywords: School absenteeism. Grade repetition. Academic failure.

Resumen: Este estudio presenta las discusiones relacionadas al absentismo escolar de los estudiantes bajo la perspectiva de los sujetos de una escuela pública en el estado de Rio de Janeiro. El artículo fue elaborado a partir de una investigación etnográfica que tuvo como resultado la tesis de maestría $L a$ clase de repetidores: un estudio etnográfico, cuyo objetivo fue observar el proceso de escolarización de los alumnos de una clase de Educación básica que constaba sólo de repetidores y multirepetidores. Este

\footnotetext{
* Mestre e doutoranda em Educação pela Universidade do Estado do Rio de Janeiro. E-mail: suziane17@yahoo.com.br
} 
estudio etnográfico utilizó los siguientes recursos, la observación participante, la entrevista etnográfica y el análisis documental, que por medio de un análisis inductivo resultó en reflexiones y discusiones acerca del proceso de escolarización de los alumnos repetidores. En reflexiones y debates con los sujetos de la investigación, el absentismo escolar está presente como una parte importante de este proceso. De esa manera, se espera que este artículo pueda contribuir para el debate y la investigación sobre el absentismo, la repetición y el fracaso escolar.

Palabras clave: Absentismo escolar. Repetición escolar. Fracaso escolar.

\section{Introdução}

O absenteísmo escolar de discentes é uma questão relevante no processo de escolarização, uma vez que se entende que a presença do aluno na sala de aula é fundamental para o desenvolvimento da aprendizagem escolar. Portanto, este estudo propõe explorar a questão do absenteísmo de discentes segundo a perspectiva dos sujeitos de uma escola pública do estado do Rio de Janeiro.

Posto isto, este artigo foi elaborado a partir de uma pesquisa etnográfica que resultou na dissertação de mestrado intitulada $A$ classe de repetentes: um estudo etnográfico, que relata questões da sala de aula observadas durante o ano letivo de 2008 em uma classe da $1^{\text {a }}$ série do Ensino Fundamental que era constituída por alunas e alunos repetentes e multi repetentes. Nesta pesquisa, fez-se uso da observação participante, de entrevistas, da análise documental e de registros de áudio e vídeo que objetivavam observar o processo de escolarização das alunas e alunos da classe de repetentes.

Portanto, nesta classe onde a pesquisa foi realizada, a falta de alunas e alunos na sala de aula era um tema recorrente, e este artigo apresenta os estudos que abordam o absenteísmo de alunas e alunos fundamentando-se teoricamente a partir de autores e pesquisadores, como Ireland (2007), Souza; Teixeira e Silva (2003), Silveira (2007), Viana et al. (2007) Sousa (2004); Casteleiro (2007) e Abramovay e Rua (2002), trazendo a regulamentação sobre o absenteísmo escolar e suas implicações para o aluno, além dos dados empíricos que ilustram os argumentos sobre o absenteísmo a partir da visão dos participantes.

Sendo assim, este artigo tem o intuito de discutir questões sobre o absenteísmo escolar de discentes, propondo um olhar mais aproximado nos sujeitos que compõem a escola e que estão direta e indiretamente envolvidos com o processo de escolarização das alunas e alunos repetentes e multirrepetentes.

\section{Conceituando o absenteísmo escolar}

O termo absenteísmo geralmente é encontrado na área de administração, sendo empregado para avaliar a rotatividade de funcionários nas empresas, determinando assim o desempenho destes. Está associado ainda a possíveis problemas em um determinado segmento da empresa, espaços em que o absenteísmo é mais frequente entre os funcionários, servindo para identificar as falhas e os ajustes necessários ao segmento.

Embora ainda pouco comum no contexto educacional, esta expressão vem se tornando cada vez mais frequente na literatura da área. Muitas vezes o termo é utilizado como um sinônimo de "faltar às aulas", entretanto, um olhar mais cuidadoso sobre o conceito revela que existem variações para o entendimento do mesmo. 
De acordo com Faro (2007), o absenteísmo escolar

constitui por si um problema individual grave na medida em que representa um entrave ao sucesso educativo de cada aluno. Pode conduzir mais tarde a situações de abandono escolar e a situações de delinquência e exclusão social levando o problema para a esfera da questão social. [...] O absenteísmo escolar, [é] entendido como a falta injustificada de comparecimento às aulas por parte de um aluno (REID, 1981). [...] quando estas faltas de assistência se sucedem de forma reiterada ou se prolongam no tempo, o ritmo de aprendizagem do aluno é afetado e, inevitavelmente, começam a surgir problemas de insucesso escolar que, se não forem solucionados rapidamente, podem conduzir a situações de abandono. [...] o absenteísmo escolar [...] constitui um dos principais fatores que contribui para o aparecimento de situações de marginalidade, delinquência e analfabetismo (GALLOWAY, SEYD; BALL, 1978). [...] quando o absenteísmo escolar obedece a fatores de tipo social ou familiar, como ocorre na maioria dos casos, então a solução para o problema converte-se num assunto complexo e, por vezes, de difícil solução (ORR, 1987). [...] um aluno que convive num seio de uma família desestruturada, ou imerso num ambiente social onde coexistem problemas sociais graves, como dependências, prostituição, delinquência, miséria, tem uma maior probabilidade de vir a engrossar as estatísticas do absenteísmo escolar (FORTIN, ROYER, POTVIN, MARCOTTE; JOLY, 2001). Uma criança ou um adolescente, que tem que se preocupar diariamente por conseguir o seu próprio sustento ou que se desenvolve num ambiente onde o nível educativo ou formativo da pessoa não é valorizado, dificilmente pode sentir-se atraído pela escola, que não oferece resultados tangíveis em curto prazo
(FORQUIN, 1985) [...] a maioria destes alunos proveem de ambientes marginais ou de zonas urbanas deprimidas e sofrem graves carências econômicas e sociais (FARO, 2007, p. 6).

O autor elenca fatores intrínsecos e extrínsecos que podem levar o aluno ao absenteísmo. Dentre os fatores intrínsecos, são citados a preparação acadêmica anterior, a saúde física e o equilíbrio pessoal, o grau de integração na escola e a satisfação acadêmica, as condutas problemáticas e o profundo desinteresse, dentre outros (Ibidem, p. 12). Os extrínsecos, explica o autor, de acordo com Gilly (1986, apud FARO, 2007, p. 12), envolvem:

Variáveis familiares: nível socioeconômico, cultural e acadêmico dos progenitores; qualidade da relação entre os membros da família, valor atribuído à escolaridade e ao trabalho, valores morais, interesse dos pais pela educação dos filhos;

Variáveis atribuíveis à dinâmica da própria escola: sistema organizativo e de coordenação, estilos de ensino dos professores, clima de convivência, ambiente percepcionado na turma e fora dela;

Variáveis referentes ao currículo: se este se apresenta atrativo na sua formulação, na sua prática etc.

O absenteísmo escolar vem sendo citado, inúmeras vezes, por Abramovay e Rua em seus estudos sobre a violência escolar (ABRAMOVAY; RUA, 2002). Nesse contexto, os autores destacam a origem do termo, definido a partir da área de administração, associando o absenteísmo às violências na escola para com os alunos; a dificuldade de registro e controle pelos professores e autoridades sobre as faltas às aulas; a preconceituosa correlação do problema à família do aluno e a relação direta entre faltas escolares 
e fracasso escolar, delinquência e pobreza. As autoras afirmam que

riscos relacionados à violência simbólica, dos quais poderíamos destacar o absenteísmo e fatores relacionados ao fracasso escolar, tais como o abandono da escola. É importante ressaltar que o absenteísmo frente a uma condição de violência social manifesta, também se associa a fatores de desigualdade social, [...] Sob o ponto de vista administrativo, o absenteísmo vem sendo definido (CHOUQUET, 1993) como um comportamento centrado na repetição de faltas voluntárias às aulas. No caso brasileiro, o Ministério da Educação trabalha a questão de forma aleatória considerando absenteístas, os alunos com determinado número de falta às aulas registradas pelos diários de classe dos professores. [...] Devido às dificuldades sistemáticas de mensurar a incidência e manifestações do absenteísmo dentro da escola e suas possíveis correlações com o fracasso escolar, tem-se estabelecido uma tendência preconceituosa em buscar na família, em especial famílias de baixa renda, os verdadeiros culpados por seus maiores níveis de incidência, reproduzindo assim perspectivas simplistas entre pobreza, delinquência juvenil e fracasso escolar (ABRAMOVAY; RUA, 2002, p. 13-14).

Uma pesquisa coordenada por Ireland (2007) aponta os desafios enfrentados pelas escolas em todo o Brasil para ensinar seus alunos a ler e escrever. Em sua apresentação o trabalho questiona a finalidade da reprovação e aponta a desistência, a repetição e o absenteísmo como parte do 'drama brasileiro’ para escolarizar seus alunos. A autora questiona:

Como se poderá entender que uma criança de seis anos de idade, no atual Ensino Fundamental de nove anos, seja uma fracassada ao fim da primeira série? Como se poderá explicar a essa criança, aos seus pais e responsáveis e à sociedade o significado da reprovação, do insucesso e da necessidade de repetir todo o ano de estudos realizados? Esta é uma das faces do drama brasileiro que se manifesta, entre outros aspectos, na desistência dos alunos ao longo dos períodos letivos ou entre eles, na repetição e na perseverança dos estudos, em média por longo tempo, e pelo absenteísmo (IRELAND, 2007, p. 17).

Mais adiante a autora associa a reprovação, a evasão e o absenteísmo entre os alunos a um indicador de exclusão social:

Sabe-se que dificuldades detectadas na educação básica estão relacionadas com problemas que vão se acumulando desde o início da escolarização de muitas crianças, aqui e ali reveladas por sinais como a reprovação, o abandono da escola e o absenteísmo, fenômenos esses que já se sabe serem também associados ao modo de funcionamento da escola e da sociedade que a comporta. Mas, na medida em que o aluno não consegue desenvolver, ao longo de sua trajetória escolar, determinadas habilidades que lhe permitam enfrentar as tarefas e exigências da sociedade e do mundo do trabalho contemporâneos, ele provavelmente será excluído da sociedade. Nesse sentido, a melhora do desempenho escolar tem uma conotação que vai muito além dos muros da escola (Ibidem, p. 19).

Mecanismos de controle, tanto para os professores quanto para os alunos, não tem garantido a frequência desses alunos, nem um maior compromisso profissional por parte dos professores em relação a suas faltas. Entretanto, enquanto o absenteísmo entre os professores é interpretado pela escola como um problema a ser resolvido pelos sistemas de ensino (federal, estadual e municipal), 
quando se trata dos alunos ele é entendido como um problema a ser resolvido pela escola, pelos pais e por instâncias do poder público judiciário, apontando que a presença dos alunos nas escolas, por si só, poderia garantir a sua escolarização, independentemente da presença do professor.

Os diversos mecanismos que regulamentam o absenteísmo entre os alunos têm sido impostos à escola sem que a mesma possa efetivamente atuar para evitar que os alunos faltem às aulas. A mais recente forma de controle está associada à política assistencial, adotada com as famílias de baixa renda, maioria nas escolas públicas - a bolsa família. Esta política social tem como condicionante a presença do aluno, nesse caso, atrelada ao recebimento da bolsa família pelo seu responsável.

De modo geral, o que observamos nas escolas pesquisadas pelo netEDU ${ }^{1}$, em 2009 e 2010, é o fato de que as escolas estão 'maquiando' os dados de frequência de seus alunos, atribuindo-lhes uma frequência total, independente da registrada pelos professores. Como justificativa, o argumento é de que "não podem agravar ainda mais a situação de pobreza dessas famílias”, mostrando, mais uma vez, que políticas assistenciais inseridas no interior da escola contribuem para demonstrar sua incompetência e fomentar um sistema de "faz de conta", comumente atribuído à área da Educação.

Esta temática não é a preocupação central deste artigo, mas se fez necessário apresentá-la para salientar o modo como são exercidos os mecanismos de controle sobre o absenteísmo, assim como os "novos” processos de avaliação e/ou a qualidade das aulas oferecidas às classes menos favorecidas que frequentam as escolas públicas.

${ }^{1}$ Núcleo de Etnografia em Educação, coordenado pela dra. Carmen Lúcia Guimarães de Mattos.
A organização existente na escola em torno da frequência evidencia que a escola ainda não se deu conta da entrada deste grupo socialmente desfavorecido. Ela continua a perpetuar um ideário elitista, de forma alienada, no qual interpreta o aluno e suas famílias como sendo os culpados pelas dificuldades e desencontros culturais existentes na mesma.

\section{Absenteísmo e instâncias reguladoras}

Sobre o absenteísmo discente, a legislação brasileira estabelece, de acordo com a constituição, em seu artigo 208, parágrafo $3^{\circ}$, que "compete ao poder público recensear os educandos no Ensino Fundamental, fazer-lhes a chamada e zelar, junto aos pais ou responsáveis, pela frequência à escola” (BRASIL, 1988).

O Estatuto da Criança e do Adolescente (ECA), criado dois anos depois da carta constitucional, insere os Conselhos Tutelares Municipais (CTs) como instâncias a serem "comunicadas" em casos de faltas "injustificadas” e "elevados” níveis de repetência, uma vez “esgotados” os recursos escolares (BRASIL, 1990), como pode ser visto a seguir:

VII -Atendimento no Ensino Fundamental, através de programas suplementares de material didático-escolar, transporte, alimentação e assistência à saúde.

[...] Art. 55. Os pais ou responsável têm a obrigação de matricular seus filhos ou pupilos na rede regular de ensino.

Art. 56. Os dirigentes de estabelecimentos de Ensino Fundamental comunicarão ao Conselho Tutelar os casos de:

I - maus-tratos envolvendo seus alunos;

II - reiteração de faltas injustificadas e de 
evasão escolar, esgotados os recursos escolares;

III - elevados níveis de repetência.

Ambos os textos, da carta magna e do ECA, foram incorporados à Lei de Diretrizes e Bases da Educação Nacional, de 1996:

Art. 24 - A educação básica, nos níveis fundamental e médio, será organizada de acordo com as seguintes regras comuns:

I - A carga horária mínima anual será de oitocentas horas, distribuídas por um mínimo de duzentos dias de efetivo trabalho escolar, excluído o tempo reservado aos exames finais, quando houver (BRASIL, 1996).

VI - o controle de frequência fica a cargo da escola, conforme o disposto no seu regimento e nas normas do respectivo sistema de ensino, exigida a frequência mínima de setenta e cinco por cento do total de horas letivas para aprovação;

Art. 12. Os estabelecimentos de ensino, respeitadas as normas comuns e as do seu sistema de ensino, terão a incumbência de:

VII - informar pai e mãe, conviventes ou não com seus filhos, e, se for o caso, os responsáveis legais, sobre a frequência e rendimento dos alunos, bem como sobre a execução da proposta pedagógica da escola; (Redação dada a Lei n 9.394/96 pela Lei $n^{0}$ 12.013, de 2009)

VIII - notificar ao Conselho Tutelar do Município, ao juiz competente da Comarca e ao respectivo representante do Ministério Público a relação dos alunos que apresentem quantidade de faltas acima de cinquenta por cento do percentual permitido em lei. (Redação dada a Lei $\mathrm{n}^{\circ}$ 9.394/96 pela lei 10.287/2001).
Entretanto, até atingir o limite de faltas (de 50 dias letivos, o equivalente a 200 horas de aula), a lei determina que medidas sejam tomadas pela escola para prevenir a ausência do aluno. O controle da frequência dos alunos é uma delas, que geralmente ocorre durante o ano letivo. Bimestralmente, professores e dirigentes escolares discutem a frequência dos alunos em Conselhos de Classe (COCs). Nos COCs, um tempo considerável da reunião é dedicado às análises da frequência de cada aluno e das possíveis implicações de suas faltas.

A atuação dos COCs dentro das escolas é regulamentada pelo Regimento Escolar. Neste caso, pela Secretaria Municipal de Educação do Rio de Janeiro (SME/RJ), que editou em abril do ano de 2010 a resolução que dispõe sobre o Regimento Escolar Básico de sua rede de ensino. O novo regimento, em seu Título V, regulamenta a organização pedagógica. O Capítulo VI trata da promoção e da frequência, e o Capítulo VII trata do Conselho de Classe, dispondo sobre seu funcionamento:

Art. 45. A promoção dos alunos dar-se-á quando atingidos os padrões mínimos estabelecidos para cada série, relativos ao aproveitamento escolar e à frequência.

Art. 46. O Conselho de Classe é o espaço democrático de tomada de decisões acerca do Projeto Político-Pedagógico da Escola, do fazer pedagógico na sala de aula e do desenvolvimento da aprendizagem do aluno.

Art. 47. Caberá ao Conselho de Classe:

I - realizar a autoavaliação da unidade escolar, enquanto instituição social, possibilitando a revisão de seu Projeto PolíticoPedagógico;

II - realizar análise diagnóstica da turma; 
III - discutir o processo pedagógico desenvolvido com as turmas, visando a seu aperfeiçoamento;

IV - analisar o desenvolvimento da aprendizagem dos alunos;

$\mathrm{V}$ - acompanhar o desenvolvimento das atividades pedagógicas propostas para potencializar o aproveitamento dos alunos;

VI - verificar a situação de frequência dos alunos, procurando-se estratégias para evitar a evasão e reprovação por esse motivo.

Art. 48. O Conselho de Classe é constituído por:

I - Direção da Unidade Escolar;

II - Equipe Pedagógica;

III - Todos os professores regentes de turma;

IV - Representantes do Conselho Escola Comunidade - CEC;

V - Representantes do Grêmio Estudantil;

Parágrafo único. O Conselho de Classe é autônomo, mas não é soberano.

(Resolução SME N 1073 de 14 de Abril de 2010)

Portanto, o COC é responsável não somente pela decisão conjunta sobre a frequência do aluno como também por seu acompanhamento e pela avaliação de seu aproveitamento. Assim, é nesse momento que a decisão de comunicar aos pais e aos CTs sobre o absenteísmo dos alunos é tomada.

Muito se tem discutido a respeito da função dos CTs (SOUZA; TEIXEIRA; SILVA, 2003; CASTRO, 2006; KAMINSI, 2002), apontados como mais uma instância de "encaminhamento" de alunos considerados "problemáticos”, marcados pela ausência ou por problemas de outra natureza. Sobre a atuação do Conselho Tutelar, um estudo realizado por Souza; Teixeira e Silva (2003), demonstra que

uma das prerrogativas do ECA refere-se à responsabilidade conjunta da escola e do CT no que se refere às ausências de alunos à escola. A escola deve comunicar ao Conselho Tutelar os casos de crianças que estão faltando muito, fornecendo-lhe nome, série e endereço, para que seus pais sejam notificados, visando saber a razão das faltas. Quando os pais não comparecem ao CT, os conselheiros podem realizar visitas domiciliares, visando a esclarecer os motivos. Independentemente de qual seja a razão das faltas, os conselheiros esforçam-se para que a criança ou o jovem volte a frequentar as aulas, conscientizando-o e à sua família sobre a importância da escolarização. Se há algum problema específico com aquela classe ou aquela escola, o conselheiro pode transferir o aluno para outro estabelecimento de ensino (SOUZA; TEIXEIRA; SILVA, 2003, p.73).

Souza; Teixeira e Silva registram a insatisfação dos conselheiros que reclamam sobre a displicência das escolas, em relação às faltas dos alunos. Segundo estes, a escola deveria encaminhar os dados dos alunos que apresentam faltas injustificadas antes de eles atingirem o limite de 25\%. De acordo com os conselheiros, esta displicência está relacionada ao sistema de ciclos e à progressão continuada, situações nas quais “o aluno passa sem saber a matéria”. Este dado também é evidenciado pelas denúncias que o CT recebe sobre "alunos que frequentam o sexto e o sétimo ano e não sabem escrever" (Ibidem, p. 75).

O estudo de Souza; Teixeira e Silva (2003, p. 74) analisou 34,8\% (trezentos e setenta e quatro) dos prontuários do total 
existente no CT pesquisado, onde $73 \%$ desses relatavam queixas provenientes de pais de alunos, e $27 \%$, queixas das escolas. Tal fato sugere que a procura dos pais para solucionar os problemas relacionados à escola é três vezes maior ao da escola para resolver os problemas de seus alunos com os pais.
Ao analisar os gráficos extraídos do estudo de Souza; Teixeira e Silva, visualizamos os motivos das queixas apresentadas aos CTs investigados, a quantidade das mesmas, os níveis educacionais a que estão relacionadas e as relações de gênero, dentre outros.

Gráfico 1 - Frequência das demandas escolares no conjunto de prontuários com informações sobre escolaridade (amostra $=130)$

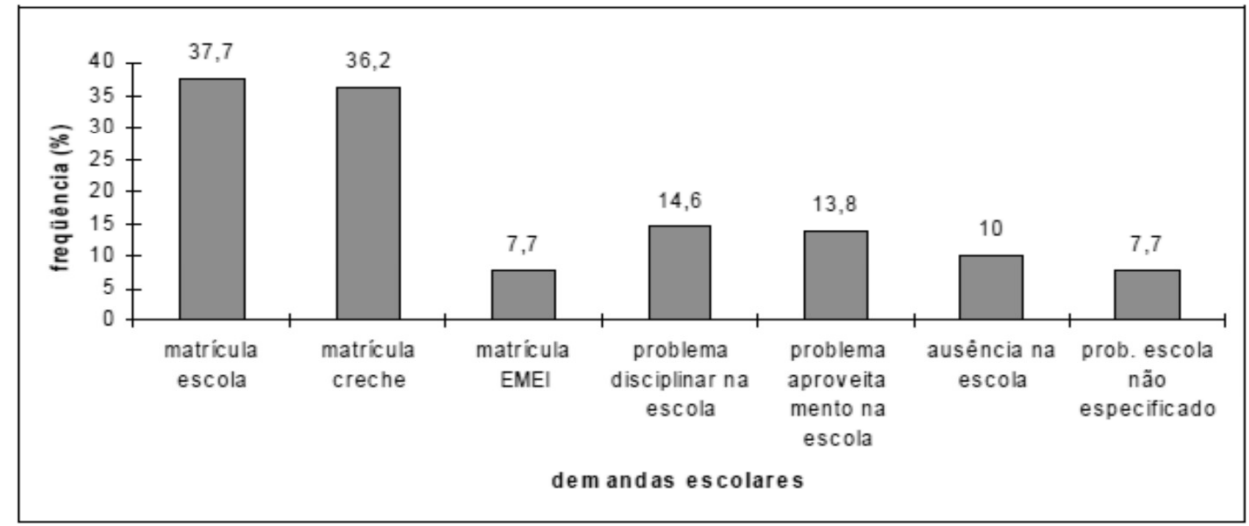

Fonte: SOUZA; TEIXEIRA; SILVA, 2003

Gráfico 2 - Frequência de queixas relacionadas a aproveitamento na escola em função do gênero $($ amostra $=18)$

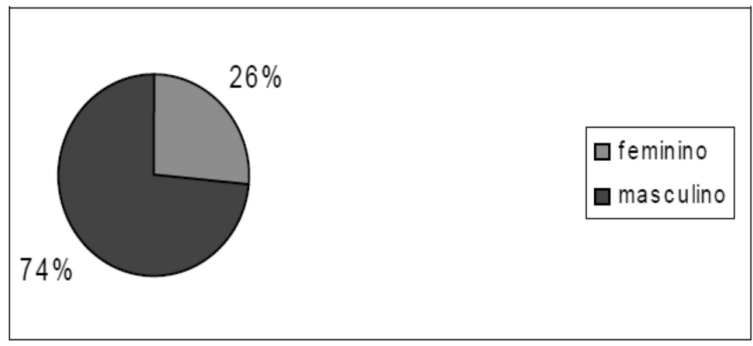

Fonte: SOUZA; TEIXEIRA; SILVA, 2003

Gráfico 3 - Frequência de queixas relacionadas a problemas disciplinares na escola em função do gênero $($ amostra $=19)$

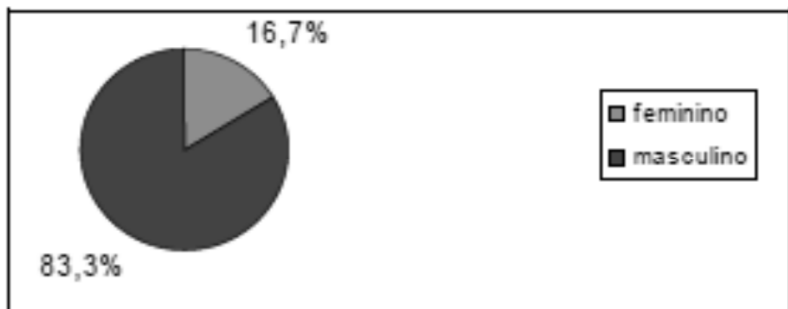

Fonte: SOUZA; TEIXEIRA; SILVA, 2003 
Gráfico 4 - Frequência de modalidades de queixas referentes a problemas na escola

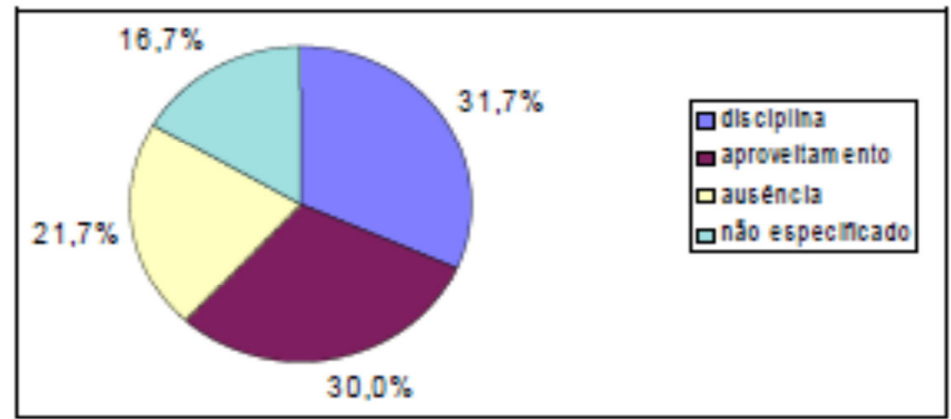

Fonte: SOUZA; TEIXEIRA; SILVA, 2003

Os dados indicam que as faltas representam $10 \%$ das queixas encaminhadas pelas escolas. As queixas disciplinares representam $14,6 \%$, do total dos prontuários analisados, deste total, 74\% estão relacionadas aos meninos, e $26 \%$, às meninas. Os problemas com aproveitamento escolar representam $13,8 \%$ das queixas. Os meninos aparecem como responsáveis por $83,3 \%$, enquanto as meninas, por $16,7 \%$.

De um modo geral, no Gráfico 4, estão representadas as queixas quanto à disciplina (31,7\%), ao aproveitamento (30,0\%), à ausência $(21,7 \%)$ e por razões não especificadas $(16,7 \%)$.

Estes gráficos demonstram o papel do CT como instância reguladora da escola, dos alunos e dos pais. Entretanto, verificamos em muitos casos que estes CTs também encontram dificuldades em lidar com os problemas que lhes são apresentados. Nas escolas pesquisadas pelo netEDU, alguns alunos se referem aos membros dos CTs como "os home”, o que significa que têm medo destas pessoas, uma vez que se reportam a elas do mesmo modo que à presença dos policiais. Nesta pesquisa foram ouvidos ainda diretores e professores, ressaltando a falta de qualificação e representatividade comunitária dos membros destes CTs.
Ainda na pesquisa etnográfica realizada em 2008 em uma escola pública do Rio de Janeiro, observou-se que na classe de repetentes, os professores, em conselhos de classe, geralmente demonstravam preocupação com o excesso de faltas de seus alunos. Uma das professoras comenta:

Eu acho que seria uma responsabilidade muito grande da escola, uma responsabilidade muito grande nossa, né? Aprovar com esse número imenso de faltas. (Professora Sônia, durante conselho de classe, 2008).

Durante essas reuniões, a interpretação dos professores sobre o número excedente de faltas dos alunos variou muito. Vários motivos foram apresentados, entre eles as relações familiares, a higiene, a saúde e a violência. A família foi mencionada inúmeras vezes como culpada pela ausência do aluno, sendo também responsabilizada por não acompanhar os filhos na escola durante o ano letivo.

As queixas das escolas sobre a falta de envolvimento dos pais nas atividades escolares e nos problemas dos filhos são recorrentes nos estudos sobre a frequência e indisciplina dos alunos. Estas queixas, em sua maioria, refletem a justificativa dos pais sobre os horários disponíveis para este 
envolvimento, feito que exigiria destes a ausência ao trabalho.

Os pais, por outro lado, queixam-se das escolas pelo fato de que, quando são chamados, geralmente é para receberem alguma reclamação sobre os filhos. Aos olhos dos pais parece existir uma "soberania do saber escolar”, espécie de poder que estaria acima deles e de seus conhecimentos a respeito dos filhos (SILVEIRA, 2007, p. 64). Esta soberania se revela, em especial, através das orientações que a escola oferece à família a respeito do comportamento das crianças e da ideia de que possuem um saber técnico e profissional sobre a educação da criança. Nesses encontros, chega-se a questionar a natureza das relações conjugais destes pais, muitas vezes interpretadas como fonte para os problemas de seus filhos.

Em sua tese a mesma pesquisadora salienta que, nas relações entre a família e a escola, os bilhetes são a forma mais usual de comunicação e que estes "possuem um caráter 'delator', queixoso e punitivo por parte do professor”. (SILVEIRA, 2007, p. 64).

As relações entre a família e a escola foram analisadas por estudos realizados por Viana (2005; 2006; 2007; 2009). Eles indicam que, muitas vezes, a escola da rede pública oferece um contexto social diferente daquele que o aluno vivencia com a família, e esta exposição simultânea a culturas divergentes pode gerar uma crise cultural no aluno. Para Viana (2007), as dificuldades vividas pelo aluno podem se desenvolver em dois campos: "aquelas vividas no contexto da experiência escolar e as vividas no bojo das relações familiares” (p. 55). A autora acrescenta que o aluno pode autodeterminar o investimento que faz em sua escolaridade, quase sempre, contando com a colaboração dos familiares, pessoas que "participam da construção do sucesso escolar dos filhos de modo diferenciado, nem sempre facilmente visível e voltado explícita e objetivamente para tal fim” (VIANA, 2007, p. 58).

Além disso, o aluno também conta com a participação da escola para a construção do seu conhecimento. Viana (2006) explica que as três esferas - família, aluno e escola - são diferenciadas e interdependentes e podem contribuir para o sucesso escolar do aluno. Neste tópico, acrescenta-se a autoculpabização dos alunos e de seus pais sobre seus resultados. Em relatório, Souza; Teixeira e Silva (2004, p. 36), explicam:

em síntese, as pesquisas que realizaram estudos de caso revelam a dificuldade dos professores para ressignificar a avaliação da aprendizagem, mantendo como suas principais finalidades decidir quanto à aprovação dos alunos ao término dos ciclos e definir quais deles deverão fazer a recuperação paralela e de férias. A manutenção, na prática, do caráter punitivo e classificatório da avaliação, também se evidencia nas manifestações de alunos. A partir de entrevistas com alunos da rede estadual, Arcas (2003) assinala que estes se posicionam como responsáveis pelos resultados que obtêm na escola, considerando as eventuais notas baixas como decorrência do fato de que não estudaram ou do acompanhamento não satisfatório de sua trajetória escolar por parte da família.

Um estudo de Ireland (2007) apresenta os casos de doença e as chuvas como às justificativas mais usadas pelos alunos e por seus pais para explicar as faltas à escola. Ao lado delas aparecem também as questões familiares, a falta dos docentes e o trabalho doméstico que realizam. A análise realizada por este estudo acrescenta ainda que a falta dos alunos é justificada, por parte dos professores, por razões que passam pelas questões familiares, de higiene, de saúde e de violência. 


\section{Justificativas e indicadores para o absenteísmo entre as alunas e alunos: evidências da pesquisa de campo realizada}

Mediante a fala dos sujeitos da pesquisa $^{2}$ foi possível perceber que a família era constantemente responsabilizada pelos professores e dirigentes pelo baixo desempenho dos alunos, assim como pelas faltas às aulas. Em entrevista, a professora Carla afirma que são poucos os pais que demonstram interesse pelo desempenho escolar dos filhos, visto que muitos deles apresentam problemas sociais:

É uma outra mãe que vem, que participa da reunião. Para a mãe vir até a escola a gente teve que insistir muito ou impedir o aluno de vir para a escola, são problemas sociais mesmo, e, ás vezes, assim, falta de interesse do pai mesmo, é falta de... é... Como é que eu vou dizer? Essa falta de interesse passa pela falta de instrução dos pais também, que é a questão social, né? Famílias envolvidas com drogas, [...] crianças que moram com padrasto e brigas familiares com a mãe, com o pai e com o padrasto... Tem até um caso de prostituição, um caso de prostituição infantil na turma [...]. Tem casos de higiene seriíssimos, seriíssimos... (Professora Carla, durante conselho de classe, 2008).

A exploração sexual infantil e a saúde, ligada à higiene, também são apontadas como possíveis causas da ausência de uma das alunas da classe de repetentes. O nome da aluna (Cláudia, de 11 anos, quatro vezes repetente) foi levado ao $\mathrm{COC}$, considerando o fato de que ela possuía 97 faltas. $\mathrm{Na}$ ocasião foi sugerido que a aluna buscasse

\footnotetext{
${ }^{2}$ Alunas e alunos da classe de repetentes, docentes e gestores da escola pública que estavam relacionados direta e indiretamente com o processo de escolarização das alunas e alunos repetentes e multirrepetentes.
}

tratamento para alguns problemas de saúde derivados da falta de higiene, tais como piolho e sarna, motivos de suas faltas, agravados pela vergonha, uma vez que foi obrigada pela família a cortar o cabelo muito curto, contribuindo com isso para que ela perdesse o interesse de voltar para escola.

De acordo com a professora Sônia, foi necessário ir à casa da aluna e conversar com a avó da menina para que ela retornasse às aulas. A conversa sobre o tema é retratada a seguir:

Eu fui buscar ela em casa, porque a escola sugeriu que ela ficasse em casa pra tratar do piolho e da sarna e não voltou nunca mais, tanto que deu 97 faltas e eu fui até a casa dela pra saber se ela tinha morrido, né? Aí cheguei lá, conversei com a avó, falei, falei, falei, e desde então ela não faltou nunca mais.

Ela teve sarna e ela teve... não justifica as 97, tá? Mas ela teve sarna e ela teve piolho. E nós sugerimos, foi até uma das falas na casa dela... mas não fomos nós que não deixamos ela ir na escola, foi a escola que sugeriu... aí eu falei: 97 dias? Porque aí não é possível, ela tem um histórico também, eu já fui preparada pra isso. Mas a justificativa é que não temos como atestar, eu não sei se isso serve também pra justificar, mas ela teve sarna e piolho e precisou ficar em casa pra se tratar, tanto que ela raspou a cabeça.

E você sabe também por que ela não está vindo, porque ela não tratou o piolho? Ela raspou a cabeça, tanto que eu comprei umas "xuxinhas" pra ela, ela falou: "Tia, tá ridículo!”, ela fica com aquela touca, eu falei: "Larissa, pelo amor de Deus, larga essa touca, olha o cheiro".

Cláudia que [...] ficou afastada da escola para tratar a sarna, que ela estava com sarna e com piolho, né... Teve até que raspar a cabeça e está usando touca o tempo 
inteiro. (Professora Sônia, durante conselho de classe, 2008).

Mariane, uma aluna de nove anos de idade, da classe de repetentes, questionada se tinha problemas com faltas, respondeu sucintamente que não, passando a falar do caso da colega de turma. Ela disse:

Não, quem falta muito é a Claúdia. [...] Ela tava com piolho, ela raspou a cabeça, por isso que ela fica com a touca. Vê só aquele negócio de chamada, tem muita falta dela... (Mariane, durante entrevista, 2008).

Ao caso da menina Cláudia, a professora Cássia acrescenta o fato de que a mãe da aluna tem um histórico de surtos e responsabiliza a avó da menina pelos problemas desta. No mesmo encontro, outras professoras mencionam a família de Cláudia, acrescentando que têm conhecimento de que a menina tem sido forçada pela família a se prostituir. A conversa foi a seguinte:

\footnotetext{
Ah, ela tem uma história. Em 2005: crianças afastadas da escola por motivos de problemas familiares. A mãe apresentou surto psicótico pedindo a saída das crianças. As crianças estão com a avó [em 2005]. Crianças estão sem uniforme porque a mãe rasgou o uniforme. [...] A mãe dela também tem um problema muito sério [...], problemas neurológicos, ela surta de vez em quando, né? E isso tudo afeta, com certeza, com certeza, eu acho que [é] isso, né? [...] Essa família... ela é completamente largada, jogada, a mãe não sabe nada, a avó não tem nenhum interesse, e eu não sei... [...]. Fica eu e o pedreiro dali, a gente fica só olhando, é um velho de bicicleta que a mãe da Cláudia vai, pega o dinheiro com ele, aí essa semana eles estavam discutindo aqui na esquina porque o velho não queria dar o dinheiro, aí o vizinho também da frente está achando que esse senhor... ela tá usando a fiIha entendeu? Está vendendo, prostituindo a filha. (Professora Cássia, durante conselho de classe, 2008).
}

Apesar dessa situação, a professora Maria defende a ideia de que a menina "tem conteúdo suficiente para ser promovida para a segunda série”. E mesmo com toda a discussão sobre as condições pessoais da vida da menina, termina por aprová-la, embora tenha sido questionada por alguns professores, com o argumento de que esta talvez não fosse uma “decisão acertada”, pois a família da menina continuaria desinteressada e isso poderia dar continuidade às faltas.

Pode-se inferir que, embora existisse a possibilidade de reprovação automática da aluna Cláudia, pelo COC e pela professora Maria, a menina não foi reprovada, o que indica que as formas de avaliação não são pautadas nas regras legais, essas só se aplicam nos casos em que tanto a professora da classe quanto o COC tem intenção de usá-las como justificativa, como poderá ser visto em alguns casos que citaremos a seguir. No caso da classe de repetentes, o que contou para a promoção da menina foi o fato de que a mesma provavelmente dominava a leitura e a escrita, saindo-se melhor que os demais alunos. Portanto, neste caso, o mérito acadêmico prevaleceu.

As violências físicas e verbais na sala de aula contribuem muito para o absenteísmo entre os alunos. A aluna Amanda, de nove anos de idade, foi um desses casos evidenciados na classe, no qual a violência motivou o desinteresse pela escola, resultando em 52 dias letivos de faltas. O nome de Amanda foi citado no COC, uma vez que se deveria decidir sobre seu destino acadêmico, visto que ela ultrapassara o limite de faltas. Na conversa no COC, foi dito que apesar do número alarmante de faltas, a aluna "lê, entende” e "escreve sob sequência lógica”.

Durante o COC não foi mencionado o motivo do absenteísmo da Amanda, mas em entrevista ela justificou que os colegas 
batiam nela e a ameaçavam. A conversa com Amanda obteve as seguintes respostas:

É muito difícil. Minha mãe fala quando eu venho pra escola, que é pra eu não brigar. E eu não brigo. Porque senão outros podem me bater, [mas] pararam já. Quem batia era o João, o Lúcio, o Alexandre, o Sandro... Só porque naquele dia, sem querer, eu entornei um copo e molhei o celular da tia, eles estavam querendo me bater na rua. Saí correndo pra casa, porque eles falaram que iam me pegar. (Amanda, aluna repetente, em entrevista, 2008).

Ao relacionar as faltas com a violência que sofre, a menina disse:

Eu faltava muito, mas agora eu tô vindo todo dia. Eu não gostava de vir pra escola não. Não gostava não, era muito ruim. Porque os garotos estavam querendo me bater, e minha mãe não mandava eu vir pra escola. Só às vezes quando os meninos não estavam na escola, ela mandava eu vir. (Amanda, aluna repetentes, em entrevista, 2008).

Da mesma forma que no caso anterior, as faltas de Amanda foram "relevadas" tanto pela professora Maria quanto pelo COC. Ela foi aprovada apesar das considerações feitas pelas professoras sobre o caso da menina. A argumentação do COC foi a seguinte:

Gente, a mesma frequência do ano passado, ano passado ela foi reprovada porque tinha 51 faltas, 74\%. Mas aí também não foi só isso. Apresenta extrema dificuldade com a leitura, então não foi só por frequência. Ela faz atendimento? [... ] Não, ô Cássia, a Roberta, irmã dela também foi reprovada por frequência, Roberta é irmã dela, foi reprovada por frequência, e ela também tem problema de frequência. [...] [Em] 2004 ela foi reprovada na nível um, por frequência. Quando chegou em 2005, ela foi aprovada. Em 2006 ela foi reprovada, não por frequência, ela teve $75 \%$, mas ela foi reprovada por conteúdo, então esse ano já é o terceiro de escolaridade. E aí, ano passado, ela ficou por frequência [...]. Agora eu vou ficar mais com a fala da professora Maria de que ela quer melhorar. Depois da conversa que você teve com ela, ela evita de faltar não é? É. Podia dar uma chance! Você acha que ela tem condições? Tem. Porque ela leu razoavelmente bem... [...] E ela tá com 52 faltas, é muito pouco, ainda mais no histórico que ela tem. (professora Sônia, conselho de classe, 2008).

Constatamos que a menina foi aprovada, mesmo ultrapassando o limite por poucas faltas. Vale a pena questionar o que pode ser considerado muito ou pouco quando temos um mínimo a ser cumprido no caso das duas meninas mencionadas anteriormente, Cláudia e Amanda.

Alexandro, de 10 anos, assim como as alunas anteriores, foi mencionado no COC por ter faltado 56 dias letivos durante o ano. Neste caso, o número de faltas, contrário aos outros citados, foi considerado muito elevado. O motivo levantado pelo COC foi a indisciplina do aluno em sala de aula, assim como a sua origem familiar, pois as professoras argumentaram que a convivência com uma família “violenta” era responsável pelo mau comportamento do menino. A conversa sobre o caso de Alexandro é apresentada a seguir:

Alexandro. Também tem 10 anos. É repetente. Ele está com 56 faltas, e ele vem pra escola, faz o que quer, e ele não aceita ser contrariado, bate na cadeira, se joga no chão. E ele lê? Ele lê, mas na hora de escrever... por exemplo, "balão" ele já escreve. Se falar bem pausado né. É, bem pausado. Também o que? Tem 11 anos? 10 ! E é o segundo ano dele, ta no segundo ano de escolaridade... Chato que já tem 
sérios problemas, né. Quem é favorável à reprovação do Alexandre? [Todos os presentes levantam as mãos] [...] Com toda essa problemática familiar dele também. [...] Pois é, e esses hábitos adquiridos que ele está né? De todo esse histórico está bastante... não, como vai ser ano que vem, não. (Conselho de classe, 2008).

Em entrevista, as professoras relataram assim o caso de Alexandro:

A questão do Alexandro... O Alexandro na verdade perdeu mais por frequência, né? Ele foi retido por frequência pela dificuldade dele, ele até sabe ler, sabe escrever, [mas] não está ainda [...] como aluno de terceiro ano que é pra onde ele iria, mas a dificuldade no Alexandre, essa reprovação dele foi mais proveniente das faltas dele, tá? (Professora Maria, em entrevista, 2008).

O Alexandro [...] vive em um ambiente de drogas e roubo [...]. Vive também a mãe com o padrasto, e a mãe esteve essa semana aqui na escola e disse que o pai ameaçou de matá-la com facas, e ele, com o irmão menor, é que foram chamar a polícia. Acredito que todo esse envolvimento familiar, não ter um ambiente tranquilo, faz com ele apresente algumas questões neurológicas [...]. Nós já solicitamos que fizesse os exames e ela até hoje não fez, né? E o papel da escola assim está sendo feito, tudo registrado, tudo assinado pela mãe também, todas as questões [...]. O Alexandre já apareceu na escola com alguns objetos que foram roubados, nós solicitamos a presença da mãe e devolvemos nas mãos da mãe. (Professora Sônia, em entrevista, 2008).

Alexandro, entretanto, tem outra versão para o absenteísmo nas aulas da professora Maria. Em entrevista, tanto ele como seu colega de classe, Felipe, afirmaram muitas vezes que faltaram as aulas por conta do absenteísmo da professora. A fala dos meninos é transcrita a seguir:

Alexandro: Ontem eu faltei porque eu fui pra minha tia e não trouxe meu material porque não tinha aula. A tia faltou.

Entrevistador: Todos foram embora?

Alexandro: Sim.

Entrevistador: Tem outra professora para substituir?

Alexandro: Não.

Entrevistador: Felipe, tem alguma coisa que você gosta na professora?

Felipe: Tem, porque ela falta aula, às vezes. (Alexandro e Felipe, alunos multirrepetentes, em entrevista, 2008).

Observamos nas discussões do COC que somente o absenteísmo dos alunos é levado em conta, a falta das professoras não foi mencionada. No caso do Alexandro, o que contou para a sua reprovação foi a associação de dois fatores: a indisciplina em sala de aula e o histórico familiar. Sobre problemas familiares, muitos casos foram mencionados no COC. Em entrevista, uma professora resume a percepção do grupo sobre o tema:

A maioria dos pais não tem interesse em acompanhar o desenvolvimento dos filhos. Acho que também tem essa coisa da família, da família em casa procurar: "Meu filho tem algum dever de casa?" Vamos sentar, vamos ver, vamos ler. Eu acho que esse apoio eles não tem em casa, a maioria, a maioria. (Professora Cássia, em entrevista, 2008).

Sendo assim, ficou evidente nas análises derivadas desta pesquisa, no que tange ao absenteísmo escolar de discentes, que as justificativas mais comuns para este foram a pobreza, associada à falta de saúde e às 
questões de higiene, e a violência, associada aos problemas familiares.

\section{Considerações finais}

O absenteísmo discente é um dos fatores que pode contribuir para a repetência escolar, pois a ausência do aluno na sala de aula pode levar o aluno à repetência automática, uma vez que o mesmo apresente quantidade de faltas superior ao preestabelecido pelo Ministério da Educação.

Entretanto, apesar de existirem regras definidas, leis e órgãos reguladores sobre o absenteísmo escolar, as análises realizadas revelam que estes não são plenamente considerados. A “autonomia relativa dos COCs”, prevista no regimento escolar, foi transformada, nos casos analisados, em "lei da escola”, uma vez que a soberania da decisão fica nas mãos dos professores, que justificam por meio do COC, com os mesmos argumentos legais, decisões diferentes.

Portanto, no presente artigo, observamos que, por conta de uma lei determinada pelo MEC, as alunas e alunos que não cumprirem $75 \%$ de frequência devem ser automaticamente reprovados. Entretanto, na classe de repetentes, a quantidade de faltas não é um fator que pode levar à repetência escolar, considerando que alunos com alto índice de absenteísmo foram considerados aptos ou inaptos para a série seguinte, tendo sido avaliados de formas diferentes pelo conselho de classe da escola. Os critérios utilizados para a aprovação ou reprovação não foram explicitados durante o conselho de classe, assim, a pesquisadora não pôde definir claramente quais foram os critérios usados para aprovar ou reprovar um aluno com alto índice de faltas. Sendo assim, este artigo não pretendeu apresentar soluções para a questão do absenteísmo, mas propiciar a discussão do absenteísmo discente em níveis que podem contribuir para a repetência de alunas e alunos no âmbito escolar, portanto, este estudo apetece contribuir para futuros estudos e discussões escolares e acadêmicas que abordem temas como o absenteísmo escolar, a repetência e o fracasso escolar.

\section{Referências}

ABRAMOVAY, M. A Violência nas Ruas: Absenteísmo e Fracasso Escolar http:// www.miriamabramovay.com/site/index. php?option=com_content $\&$ view $=$ section $\&$ layout $=$ blog\&id $=5 \&$ Itemid $=2$ acesso em 21/08/2010.

ABRAMOVAY, M.; RUA, M. G. Violências nas Escolas. Brasília: Unesco, 2002.

BRASIL, Lei $\mathrm{n}^{\circ}$ 9.394, de 20 de dezembro de 1996. Estabelece as Diretrizes e Bases da Educação Nacional. Presidência da República, Brasília, 1996. Disponível em: <http://www.planalto.gov.br/ccivil_03/leis/ 19394.htm>. Acesso em: 12 fev. 2010

\section{Constituição (1988). Constituição}

da República Federativa do Brasil: promulgada em 5 de outubro de 1988. Brasília, 1998. Disponível em: <http:// www.planalto.gov.br/ccivil_03/constituicao/ constituicaocompilado.htm>. Acesso em: 17 fev. 2010

, Lei $n^{\circ}$ 8.069, de 13 de julho de 1990. Dispõe sobre o Estatuto da Criança e do Adolescente e dá outras providências. Presidência da República, Brasília, 1990. Disponível em: <http://www.degase.rj.gov. br/documentos/ECA.pdf $>$. Acesso em: 22 fev. 2010

CANDAU, V. M. Direitos humanos, educação e interculturalidade: as tensões entre igualdade e diferença. In: Revista 
Brasileira de Educação, v. 13, n. 37, p. 4556, 2008.

CASTELEIRO, Steven M.B. Dossier de Imprensa: Realidade escolar actual. Problemas Sociais do Mundo Contemporâneo. Dissertação de Mestrado em Educação Social e Comunitária pela Universidade da Beira Interior, Covilhã, Portugal, 07 de Dezembro de 2007.

CASTRO, P. A. Controlar para quê? Uma análise etnográfica do controle na interação entre professor e aluno na sala de aula. 2006. 187f. Dissertação (Mestrado em Educação) Programa de Pós-Graduação em Educação, Universidade do Estado do Rio de Janeiro.

CHOUQUET, M.; HASSLER, C. Absentéisme au lycée: Les dossier d'education et formations. Paris: Ministère de l'éducation nationale, de la recherche et de la technologie, 1993.

FARO, Divisão de Acção Social, Análise da relação entre o perfil psicossocial do aluno e o abandono escolar. Projecto "Integrar para Educar”- Programa Ser Criança. Ministério do Trabalho e Solidariedade Social, da Câmara Municipal de Faro. Portugal, 2007.

FLETCHER, R.P.; RIBEIRO, S.C.Aeducação na estatística nacional. In: SAWYER, D. O. (Org.). PNADs em foco: anos 80. Belo Horizonte: Associação Brasileira de Estudos Populacionais - ABEP, 1988.

GALLOWAY, D.; SEYD, R.; BALL, T. Absence from school and behaviour problems in school. Therapeutic Education, London, vol. 6, n. 2, p. 28-33, 1978.

GILLY, M. Psicosociología de la educación. Buenos Aires: Paidós. 1986

GOUVÊA, G. F. P. Um Salto para o presente: a educação básica no Brasil. São Paulo em Perspectiva, vol. 14, n. 1, 2000.
IRELAND, V. E. (Coord.). Repensando a escola: um estudo sobre os desafios de aprender, ler e escrever. Brasília: UNESCO; MEC/INEP, 2007.

KAFURI, R.; RAMON, S. P. Pesquisa sobre evasão, repetência e fatores condicionantes: relatório $-1^{\circ}$. grau, casos e percalços. Goiânia : UFG/FAE, 1985.

KAMINSI, A. K. O conselho tutelar, a criança e o ato infracional: proteção ou punição? Canoas. Ulbra, 2002.

MAINARDES, J. Organização da escolaridade em ciclos no Brasil: revisão da literatura e perspectivas para a pesquisa. Educação e Pesquisa. São Paulo, v. 32, n. 1, p. 1129, jan./abr. 2006. Disponível em: <http:// www.scielo.br/scielo.php?script=sci_artt ext\&pid=S1517-97022006000100002 > Acesso em: 25 mar. 2010

NERI, M. C.; COSTA, D. R. da. O Tempo das Crianças. Ensaios Econômicos, Rio de Janeiro, n468, 2002. Disponível em: <http:// bibliotecadigital.fgv.br/dspace/bitstream/ handle/10438/532/1316.pdf? sequence=2 $>$. Acesso em: 10 fev. 2010

PAZELLO, E. T.; FERNANDES, R.; FELICIO, F. Incorporando o atraso escolar e as características sócio-demográficas nas taxas de transição educacional: um modelo de fluxo escolar. XXXIII Encontro Nacional de Economia, 2005. Disponível em: <http:// www.anpec.org.br/encontro2005/artigos/ A05A155.pdf>. Acesso em: 17 mar. 2010.

REID, K. C. Alienation and persistent school absenteism. Research in Education, n. 29, p. 31-40, 1981. Disponível em: <http:// psycnet.apa.org/psycinfo/1982-24418-001> Acesso em: 27 mar. 2010.

SILVEIRA L. M. DE O. B. A Interação Família-escola frente aos Problemas de Comportamento da Criança: uma parceria 
possível? Tese apresentada no Curso de Doutorado em Psicologia da Faculdade de Psicologia da Pontifícia Universidade Católica do Rio Grande do Sul, para a obtenção do Título de Doutor em Psicologia: Porto Alegre 2007.

SOUSA, S. M. Z. L.; BARRETTO, E. S. de S. (Coords.). Estado do Conhecimento Ciclos de progressão escolar (1990-2002): relatório final. São Paulo: FEUSP, out. 2004.

SOUZA, M. P. R.; TEIXEIRA, D. C. da S.; SILVA, M. C. Y. G. da. Conselho Tutelar: um novo instrumento social contra o fracasso escolar? Psicologia em Estudo, Maringá, vol. 8, n. 2, jul./dez. 2003. Disponível em: <http://www.scielo.br/scielo.php?pid=S141 373722003000200008\&script=sci_arttext $>$. Acesso em: 17 mar. 2010.

VIANA, Maria José Braga (et al). Longevidade escolar em famílias populares: algumas condições de possibilidade. Goiânia: Editora da UCG, apoio Fapemig, 2007.

Enviado em: 11. Jul. 13

Aceito em: 09. Abr. 14 